Trakya Eğitim Dergisi

Cilt 9, Sayı 2

Mayıs 2019, 366-379

Gelis Tarihi: 11.16.2018

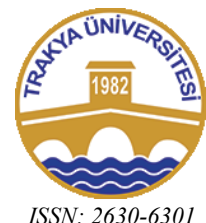

ISSN : 2630-6301
Trakya Journal of Education

Volume 9, Issue 2

May 2019, 366-379

\title{
Bilimin Doğası Kapsamında Gözlem: Meteoroloji Gözlem Etkinliği Örneği
}

\section{Observation in Nature of Science: Example of Meteorology Observation Activity}

\author{
Gülşah ULUAY' Nihat ARIKAN $^{2}$
}

\begin{abstract}
Öz: Bu çalışmanın amacı fen bilgisi öğretmen adaylarının gözlem yapmalarını ve yaptıkları gözlemler aracılığıyla hava durumuna ve bilimsel bilginin niteliklerine ilişkin çıkarımlarda bulunmalarını sağlamaktır. Nitel verilerden oluşan çalışma, durum araştırması desenine göre dizayn edilmiştir. Çalışma süreci 2017-2018 bahar döneminde fen bilgisi eğitimi anabilim dalı 4. sınıfında öğrenim görmekte olan ve astronomi dersine devam eden 64 öğretmen adayı ile yürütülmüştür. Araştırma verileri yarı-yapılandırılmış görüşme formu ve doküman aracıllı̆ıyla toplanmıştır. Veri analiz sürecinde içerik analizi yöntemi kullanılmıştır. Araştırma sonuçlarına göre, öğretmen adaylarının gözlem etkinliği süreci öncesinde günlük yaşamda karşılaştıkları ve gözlemledikleri olayları bilimsel açıdan değerlendirme noktasında eksiklik yaşadıkları görülmüştür. Etkinlik süreci sonrasında ise öğretmen adaylarının gözlemledikleri olayları eleştirel olarak değerlendirmeye ve bilimin doğasına ilişkin niteliklere odaklanarak açıklamaya başladıkları görülmüştür.
\end{abstract}

Anahtar sözcükler: Bilimin doğası, gözlem, meteoroloji, öğretmen adayl

\begin{abstract}
The aim of this study is to make pre-service science teachers observe and to make inferences about weather conditions and the characteristics of scientific knowledge through observations. The study which is composed of qualitative data is designed according to the case study design. The study was carried out with 64 pre-service science teachers who were studying in the 4th year of science education department in the spring term of 2017-2018 and attending astronomy lesson. The research data were collected through semi-structured interview form and document. Content analysis method was used in data analysis process. According to the results of the study, it was seen that preservice teachers showed deficiencies about evaluating cases encountered and observed in daily life scientifically before the observation activity period. After the activity process, it was seen that pre-service teachers started to critically evaluate cases which they observed and explain them by focusing on the qualities related to the nature of science.
\end{abstract}

Keywords: Nature of science, observation, meteorology, preservice teacher

\section{EXTENDED ABSTRACT}

\section{Introduction}

Helping students to develop their understandings about the nature of science has been one of the most common goals for science education (Kimball, 1967). The nature of science is used to express the epistemology of science, the science as a method of knowing, or the values and beliefs specific to the development of scientific knowledge (Abd-El-Khalick, Bell, \& Lederman, 1998).

Lederman (2013) states that students should understand the critical distinction between observation and inference. Observations are obtained through human senses or extensions of these senses (Schwartz, Lederman, \& Crawford, 2004). Indeed, observations are explanatory statements about natural phenomena that can be directly accessed by senses (or sense extensions) and where various observers can reach consensus with relative ease (eg, explanations of the morphology of the remains of a living organism) (Lederman, 2013). In other words, anything that the individual can see, hear, smell, taste or touch through his senses or obtain by means of various tools (eg, telescopes) that increase his senses is described as observations (Nokes, 2008). The inferences that go beyond the senses (Lederman, 2013) are interpretations of these observations (Schwartz, Lederman, \& Crawford, 2004). In other words, inferences are based on knowledge based upon observations made by an individual (Nokes, 2008). For example, explanations about the morphology of the observed morphology can be developed in terms of their possible contribution to the function. On a higher level, a scientist can make sense of the model or mechanisms that explain the observations of complex phenomena such as weather, evolution (Lederman, 2013).

\footnotetext{
${ }^{1}$ Arş. Gör., Ahi Evran Üniversitesi, Eğitim Fakültesi, Matematik ve Fen Bilimleri Eğitimi Bölümü, gulsahuluay@ahievran.edu.tr, ORCID: 0000-0002-6365-5122

${ }^{2}$ Doç. Dr., Ahi Evran Üniversitesi, Eğitim Fakültesi, Matematik ve Fen Bilimleri Eğitimi Bölümü, narikan@ahievran.edu.tr, ORCID: 0000-0001-8028-3132
} 
Individual perception towards the limitation of observation to the perceptual equipment of individuals and on the basis of the theory of nature is seen as part of the individual's understanding of the nature of science (Abd-El-Khalick, Bell, \& Lederman, 1998). From this point of view, it can be stated that in the development of an individual's understanding about the nature of science making an observation, the observation conditions and evaluating the results of observation is important. In this context, the aim of this study is to make pre-service science teachers observe and to make inferences about weather conditions and the characteristics of scientific knowledge through observations. For this purpose, pre-service science teachers participated in the meteorological observation activity process.

\section{Method}

In this research, a case study design was used. Within the scope of case studies, an in-depth investigation of a specific system with certain limits such as activity, individuals, process or event is involved (Creswell, 2013). This research was carried out with 64 pre-service teachers in the fourth year of science education in the Faculty of Education.

During the out-of-school activity process called meteorological observation activity, pre-service teachers conducted the 75-day observation process and recorded their observation notes. Smart weather applications such as Weather, AccuWeather and The Weather Channel were used in the activity period. At this point, it is aimed that pre-service teachers will be able to evaluate the weather reports that they can easily access or frequently encounter. During the observation period, the weekly weather forecasts presented by the applications were recorded firstly in the observation recording chart by pre-service teachers. Daily weather forecasts received from the applications were examined every day and added to the chart.

In the research, semi-structured interview form and document were used as data collection tools. Content analysis was used in the analysis process.

\section{Result and Discussion}

It has been concluded that pre-service teachers showed deficiencies in questioning and evaluating the cases which they encountered in daily life. In the nature of science education, it is emphasized the importance of critically evaluating the cases faced by individuals in daily life within the framework of interactions between science, technology and society (Albe, 2008). In addition to this, it was concluded that pre-service teachers started to make inferences by interpreting the results of observations that they had obtained within the framework of meteorological observation activity. As a matter of fact, it was seen that the pre-service teachers who explained that they believe in the application data before the activity process and that the data is certain are informed that the results determined by the observation data can change after the completion of the activity. From this point of view, it is considered that it is important to create observation for pre-service teachers to evaluate the world with a critical point of view and to have more experience in this point. For example, a variety of observational activities including cases in the world of living beings such as changes in trees and animal migration can be organized.

\section{GíRIŞ}

Öğrencilerin bilimin doğasına yönelik kavrayışlarının gelişmesine yardımcı olunması, fen eğitimi için en sık belirtilen hedeflerden biri olmuştur (Kimball, 1967). Bilimin doğası bilimin epistemolojisini, bilme yöntemi olarak bilimi ya da bilimsel bilginin gelişimine özgü değerleri ve inançları ifade etmek için kullanılmaktadır (Abd-El-Khalick, Bell, \& Lederman, 1998). Bu genel karakteristiklerin ötesinde, bilim felsefecileri, bilim tarihçileri, bilim insanları ve bilim eğitimcileri arasında bilimin doğasına ilişkin özel bir tanım üzerinde herhangi bir fikir birliği mevcut değildir (AbdEl-Khalick \& Lederman, 2000). Bu durumun nedeni, bilimsel bilginin niteliklerine benzer şekilde bilimin doğasına yönelik kavramların geçici ve dinamik olması ile açıklanmaktadır (Lederman, AbdEl-Khalick, Bell, \& Schwartz, 2002).

Schwartz, Lederman ve Crawford (2004) bilimin doğasına ilişkin nitelikleri şu şekilde sıralamaktadır: (1) geçicilik, (2) deneysel dayanak, (3) öznellik, (4) yaratıcılık, (5) sosyokültürel yapı, (6) gözlem ve çıkarım, (7) yasalar ve teoriler, ve (8) her bir niteliğin birbirine bağlı oluşu. Geçicilik 
kavramı ile bilimsel bilginin yeni gözlemlerle ve var olan gözlemlerin yeniden yorumlanmasıyla değişime tabi olması ifade edilmektedir. Deneysel dayanak, bilimsel bilginin doğal dünyanın gözlemlerine dayanması ve / veya bu gözlemlerden elde edilmesi özelliğini vurgulamaktadır. Öznellik niteliği ile bilimin halen kabul edilen bilimsel teoriler ve yasalardan etkilenmekte ve bu yasa ve teoriler aracılığıyla yönlendirilmekte olduğu açıklanmaktadır. Nitekim soruların, araştırmaların ve veri yorumlamalarının gelişimi, mevcut teorinin merceğinden süzülmektedir. Bu durum bilimin ilerlemesine ve tutarlı kalmasına imkân veren kaçınılmaz bir öznelliktir. Ayrıca önceki kanıtlar yeni bilgi perspektifinden incelendiğinde bilimde değişime de katkı sağlanmaktadır. Kişisel değerler, gündemler ve önceki deneyimler, bilim insanlarının işlerini nasıl yürüttüğünü etkilemekte ve bu bağlamda kişisel öznellik de kaçınılmaz olmaktadır. Yaratııılık bilimsel bilginin hayallerden ve mantıksal çıkarımlardan oluştuğunu simgelemektedir. Sosyokültürel yapı bilimin bir insan çabası olduğuna değinmektedir. Bu nedenden dolayı bilim, uygulandığı toplum ve kültürden etkilenmektedir. Nitekim kültür değerleri bilimin nasıl yürütüldüğünü, yorumlandığını, kabul edildiğini ve kullanıldığını belirlemektedir. Gözlem ve çıkarım niteliği ile bilimin hem gözlem hem de çıkarım üzerine kurulu olmasının altı çizilmektedir. Mevcut bilim ve bilim insanı perspektifleri hem gözlemleri hem de çıkarımları yönlendirmekte ve çoklu perspektifler, gözlemlerin geçerli çoklu yorumlarına katkıda bulunmaktadır. Yasalar ve teoriler ise bilimsel bilginin farklı türleridir. Kanunlar, doğadaki fenomenlerin gözlenen veya algılanan ilişkilerini tanımlar. Teoriler, doğal fenomenler ve doğal fenomenler arasındaki ilişkilere dair mekanizmalar için çıkarımlardır. Bilimdeki hipotezler, bilimsel toplulukta önemli destekleyici kanıtların ve kabulün birikimi ile teorilere veya yasalara yol açabilir. Kuramlar ve yasalar, hiyerarşik anlamda, birbirinden ayrı ve işlevsel olarak farklı bilgi türleri olduğu için, bir diğerine ilerlemezler. Her bir niteliğin birbirine bağlı oluşu ile söz konusu niteliklerin hiçbirinin diğerlerinden ayrı düşünülemeyeceğine dikkat çekilmektedir. Örneğin, bilimsel bilginin tentativitesi, bu bilginin ampirik gözlem ve çıarım yoluyla yaratılmasından kaynaklanmaktadır. Bu eylemlerin her biri, bilimin uygulandığı kültür ve toplumun yanı sıra bilim insanının kuramsal çerçevesi ve kişisel öznelliği tarafından etkilenir. Yeni veriler göz önüne alındığında ve mevcut veriler yeniden gözden geçirildikçe, çıkarımlar (yine belirli bir bağlamda yapılır) mevcut bilimsel bilgide değişikliklere yol açabilir (Schwartz, Lederman, \& Crawford, 2004).

Lederman (2013), öncelikli olarak öğrencilerin gözlem ve çıkarım arasındaki kritik ayrımı anlamaları gerektiğini ifade etmektedir. Gözlemler insan duyuları veya bu duyuların uzantıları aracılığıyla elde edilmektedir (Schwartz, Lederman, \& Crawford, 2004). Gözlemler, duyularla (ya da duyu uzantılarıyla) doğrudan erişilebilen ve çeşitli gözlemcilerin göreceli kolaylık ile görüş birliğine varabildikleri (örneğin, bir zamanlar yaşayan bir organizmanın kalıntılarının morfolojisine ilişkin açıklamalar) doğal fenomenler hakkındaki açıklayıcı ifadelerdir (Lederman, 2013). Yani, bireyin duyuları aracılığıyla görebildiği, duyabildiği, koklayabildiği, tadabildiği veya dokunabildiği ya da duyularını artıran çeşitli araç gereçler vasıtasıyla (örneğin, teleskop) elde ettiği herhangi bir şey gözlem olarak betimlenmektedir (Nokes, 2008). Duyuların ötesine geçen çıkarımlar (Lederman, 2013) ise bu gözlemlerin yorumlarıdır (Schwartz, Lederman, \& Crawford, 2004). Yani, çıkarımlar bir bireyin yaptı̆̆ gözlemlere odaklana bilgiye dayalı tahminlerdir (Nokes, 2008). Örneğin, gözlenen morfolojinin fonksiyona muhtemel katkıları açısından söz konusu morfoloji hakkında açıklamalar geliştirilebilir. Daha yüksek bir seviyede, bir bilim insanı hava durumu, evrim gibi karmaşık fenomenlerin gözlemlerini açıklayan model ya da mekanizmalara ilişkin anlam çıkarabilir (Lederman, 2013).

Gözlemin bireylerin algısal donanımlarıyla sınırlandırılmasına ve doğası gereği teoriye dayalı olmasına yönelik bireysel algı, bireyin bilimin doğasına yönelik kavrayışının bir parçası olarak görülmektedir (Abd-El-Khalick, Bell, \& Lederman, 1998). Bu bakış açısından hareketle, bir bireyin bilimin doğasına yönelik anlayışının gelişmesinde gözlem yapma, gözlem koşulları ve gözlem sonuçlarını değerlendirme konularının önemli olduğu belirtilebilir. Bu bağlamda, bu çalışmanın amacı fen bilgisi öğretmen adaylarının gözlem yapmalarını ve yaptıkları gözlemler aracılığıyla hava durumuna ve bilimsel bilginin niteliklerine ilişkin çıkarımlarda bulunmalarını sağlamaktır. Bu amaç doğrultusunda, fen bilgisi öğretmen adayları meteoroloji gözlem etkinliği sürecine katılmıştır. 


\section{YÖNTEM}

$\mathrm{Bu}$ çalışma, nitel araştırma desenindedir. Denzin ve Lincoln (2000)'e göre nitel araştırma, dünyadaki gözlemciyi konumlandıran yerleşik bir aktivitedir ve bu desen dünyaya yönelik yorumsal, natüralist bir yaklaşımı içermektedir. Araştırmacılar nitel araştırmanın barındırdığı saha notları, görüşmeler, söyleşiler, fotoğraflar, kayıtlar ve notlar gibi çeşitli uygulamalar ile dünyanın bir dizi temsile dönüştürüldügünü ifade etmektedir. $\mathrm{Bu}$ araştırmada, nitel araştırma türlerinden durum araştırması deseni kullanılmıştır. Durum araştırmaları kapsamında etkinlik, bireyler, süreç ya da olay gibi belirli sınırlara sahip olan belirli bir sistemin derinlemesine araştırılması söz konusudur (Creswell, 2013).

Durum araştırması kapsamında yürütülen ve meteoroloji gözlem etkinliği odaklı bu araştırmanın problemleri şu şekildedir:

1. Katılımcılar günlük yaşamda karşılaştıkları olayları bilimsel açıdan nasıl değerlendirmektedir?

2. Katılımcılar gözlemin bilimdeki yerini nasıl değerlendirmektedir?

\subsection{Katılımcilar}

$\mathrm{Bu}$ araştırmanın çalışma grubu, 2017-2018 bahar döneminde eğitim fakültesi fen bilgisi eğitimi anabilim dalı 4. sınıfında öğrenim görmekte olan 64 öğretmen adayı ile yürütülmüştür. Tüm öğretmen adayları astronomi dersine devam etmektedir. Katılımcıların 53'ü kadın $(\% 82,8)$ ve 11'i erkektir $(\% 17,2)$.

\subsection{Uygulama Süreci}

İnsanoğlunun dünyaya bakış açısını tarih boyunca şekillendiren astronomi, ilk gelişen bilim olarak anılmaktadır (Lightman, 1999). Bu durum üzerinde, insanoğlunun içerisinde yaşadığı ve ulaşılmaz gördüğ̈̈ evreni anlama dürtüsü ve bu dürtüden dolayı insanlığın en çok ilgisini çeken konular arasında yer alan gökbilimin (Akoğlu, 2005) de etkili olduğu belirtilebilir. Doğadaki düzenliliğin ilk örnekleri olan gök cisimlerinin hareketleri ve mevsimsel değişimleri (Lightman, 1999) kapsayan gökyüzü gözlemi, kolaylıkla uygulama yapma imkânı sunmaktadır (Şener, Demirhan, \& Kalyoncu, 2005). Bu bağlamda, bu çalışma kapsamında meteoroloji gözlem etkinliği düzenlenmiştir. Bu etkinliğin amacı, bilimsel süreçler çerçevesinde gözlemin bilimin doğasına ilişkin nitelikler içerisindeki yeri ve öneminin fen bilgisi öğretmen adayları tarafından incelenmesidir. Söz konusu amaç doğrultusunda, gözlem süreçlerinin nasıl ve hangi koşullara bağlı olarak gerçekleştirilebileceğinin araştırılması ve bilimsel yollarla elde edilen veri ve sonuçlarının değerlendirilmesi yapılmıştır. Uygulama süreci, 2017 - 2018 eğitim öğretim yılı bahar döneminde astronomi dersi kapsamında fen bilgisi eğitimi anabilim dalı son sınıf öğrencileri ile yürütülmüştür.

Astronomi dersi kapsamında gökyüzü gözlemleri ve bu gözlemlerin astronomideki önemi ele alınmıştır. Nitekim astronomi tarihi incelendiğinde, gözlem ve astronomi arasındaki bağlantının çok eski dönemlere dayandığı görülmektedir. Örneğin, tutulma gözlemlerinin Babil astronomisinde oldukça önemli bir yere sahip olduğu ifade edilmektedir (Unat, 2003). Bu bağlamda, öğretmen adaylarının kolaylıkla takip edebilecekleri bir gözlem sürecine meteoroloji gözlem etkinliği ile katılmaları ve gözlem süreçlerini deneyimlemeleri hedeflenmiştir. Meteoroloji gözlem etkinliği şeklinde adlandırılan okul dış1 etkinlik sürecinde öğretmen adayları 75 günlük gözlem sürecini yürütmüş ve gözlem notlarını kaydetmiş̧lerdir. Etkinlik kapsamında Hava Durumu, AccuWeather, The Weather Channel gibi akıllı telefon uygulamaları kullanılmıştır. Bu noktada, öğretmen adaylarının kolaylıkla erişebildikleri ya da sıklıkla karşılarına çıkan hava durumu haberlerini bilimsel açıdan değerlendirmeleri amaçlanmıştır. Belirlenen gözlem süresi kapsamında, gözlem kayıtları oluşturulurken öncelikle uygulama tarafından sunulan haftalık hava tahminleri öğretmen adayları tarafından gözlem kayıt çizelgesine kaydedilmiştir. Uygulamalardan alınan günlük hava tahminleri ise her gün incelenmiş ve kayıt çizelgesine eklenmiştir. Haftalık ve günlük olarak kaydedilen bu veriler sabah, öğle ve akşam saatleri olmak üzere incelenmiş ve gözlem kayıtlarına dâhil edilmiştir. Ayrıca öğretmen adayları her gün sabah, öğle ve akşam olmak üzere hissettikleri ve karşılaştıkları hava koşullarını kaydederek uygulamadan elde ettikleri veriler ile karşılaştırmışlardır. 


\subsection{Veri Toplama Araçları}

$\mathrm{Bu}$ çalışma, nitel verilerden oluşmaktadır. Araştırmada veri toplama aracı olarak yarıyapılandırılmış görüşme formu ve doküman kullanılmıştır. Görüşme yöntemi ile yürütülen bir veri toplama süreci kapsamında katılımcılara genel ve açık uçlu sorular sorulmakta ve katılımcıların ifade ettiği yanıtlar kaydedilmektedir (Creswell, 2012). Görüşme yöntemi, bireylerin yaşadıkları dünyaya ilişkin yorumlarını tartışmaları ve deneyimledikleri durumları kendi bakış açılarıyla nasıl ele aldıklarını ifade etme noktasında imkân sunmaktadır (Cohen, Manion, \& Morrison, 2007). Bu çalışmada, yarıyapılandırılmış görüşme formunun tercih edilme nedeni, bu yöntemin farklı katılımcılarla farklı görüşme süreçlerinin yürütülmesi noktasında yeterli esnekliği sağlaması (Noor, 2008) olarak ifade edilebilir. Nitekim bu tekniğin sunduğu esneklik özelliği sayesinde katılımc1lara tamamlayıcı sorular sorularak görüşme süreçleri yürütülmüştür. Her bir öğretmen adayı ile meteoroloji gözlem etkinliği sürecinin başlangıcında ve sonunda olmak üzere iki kez görüşme yapılmıştır. Süreç başlangıcında kullanılan yarı-yapılandırılmış görüşme formu 6 sorudan oluşmakta ve sürecin tamamlanmasının ardından yürütülen görüşme süreci için hazırlanan form 2 soru içermektedir. Görüşme sorularının hazırlanması aşamasında üç uzmandan görüş alınmıştır. Uzman görüşleri doğrultusunda hazırlanan taslak formlar, araştırmacılar ve uzmanların katılımıyla gerçekleştirilen bir oturum kapsamında değerlendirilmiş ve nihai görüşme soruları oluşturulmuştur.

Görüşme süreçlerinin başlangıç aşamasında her bir katılımcıya görüşmenin amacı açıklanmış ve kimlik bilgilerinin gizli tutularak bu görüşmelerin üçüncü şahıslarla paylaşılmayacağı bilgisi verilmiştir. Ardından ses kaydı için izin alınarak görüşmeler yapılmıştır.

Tablo 1. Yar1-yapılandırılmış görüşme formu

\begin{tabular}{|c|c|c|}
\hline & $\begin{array}{c}\text { Etkinlik Başlangıcında Kullanılan Görüşme } \\
\text { Formu }\end{array}$ & $\begin{array}{c}\text { Etkinlik Sonunda Kullanılan Görüşsme } \\
\text { Formu }\end{array}$ \\
\hline 1 & $\begin{array}{l}\text { Cep telefonunuzda kullandığınız herhangi bir } \\
\text { hava durumu uygulaması var mı? Varsa } \\
\text { lütfen adını belirtiniz. }\end{array}$ & $\begin{array}{l}\text { Hava durumu uygulamanızdan kaydetmiş } \\
\text { olduğunuz haftalık veriler ve günlük veriler } \\
\text { ile gün içerisinde yaşadığınız hava } \\
\text { koşullarının benzerlik gösterme/göstermeme } \\
\text { durumu hakkında bilgi veriniz. }\end{array}$ \\
\hline 2 & $\begin{array}{l}\text { Hava durumu uygulamanızı ya da meteoroloji } \\
\text { haberlerini hangi sıklıkta takip edersiniz? }\end{array}$ & $\begin{array}{l}\text { Uygulamanın sunmuş olduğu veriler ile } \\
\text { yaşamış olduğunuz hava koşulları arasındaki } \\
\text { uyuşmazlıkların nedenlerini tartışınız. }\end{array}$ \\
\hline 3 & $\begin{array}{l}\text { Hava tahminlerinden edindiğiniz } \\
\text { açılamalara inanma düzeyiniz hakkında bilgi } \\
\text { veriniz. }\end{array}$ & \\
\hline 4 & $\begin{array}{l}\text { Hava tahminleri aracılığıyla edindiğiniz } \\
\text { bilgileri, gün içerisinde karşılaştığınız hava } \\
\text { koşulları ile kıyaslar mısınız? }\end{array}$ & \\
\hline 5 & $\begin{array}{l}\text { Meteorolojik halk takvimi denildiğinde ne } \\
\text { anlıyorsunuz? }\end{array}$ & \\
\hline 6 & $\begin{array}{l}\text { Pastırma sıcakları, koca karı soğukları gibi } \\
\text { hava koşulları hakkındaki düşüncelerinizi } \\
\text { lütfen açıklayını. }\end{array}$ & \\
\hline
\end{tabular}

Bir doküman içeriğinde, nitel bir araştırma kapsamındaki katılımcılara ilişkin bilgi edinmek amacıyla kullanılan kişisel ya da toplumsal kayıtlar bulunmaktadır (Creswell, 2012). Örneğin, zaman çizelgeleri, öğrenci çalışmaları örnekleri, birincil ve ikincil kaynaklar, alan notları, anı defterleri ve yazışmalar doküman kapsamında incelenmektedir (Cohen, Manion, \& Morrison, 2007). Bu çalışmada, katılımcıların hazırlamış oldukları zamana bağlı gözlem kayıtları incelenmiş̧tir. Bu bağlamda, araştırma kapsamında kullanılan doküman birincil kaynak niteliğindedir (Cohen, Manion, \& Morrison, 2007). 


\subsection{Veri Analizi}

$\mathrm{Bu}$ çalışmada nitel analiz yöntemlerinden içerik analizi kullanılmıştır. İçerik analizi, transkripsiyonu yapılan nitel verilerin içeriğindeki tekrarlanan ifade ve durumların tespit edilerek söz konusu tekrarlamalar 1şığında geçerli çıkarımlar elde edilmesine olanak sağlayan bir yöntemdir (Krippendorff, 2004). Bu çalışmanın veri analizi süreci, Creswell (2012) tarafından ifade edilen adımlar aracılığıyla yürütülmüştür: (1) verilerin toplanması, (2) yürütülen iki görüşme süreci aracılığıyla elde edilen ses kayıtlarının transkript edilerek analiz için hazırlanması, (3) elde edilen metne ilişkin genel bir bakış açısı edinmek amacıyla metnin okunması, (4) verilerin kodlanması.

\section{BULGULAR}

\subsection{Meteoroloji Gözlem Etkinliği Başlangıcındaki Görüşme Bulguları}

Görüssme Sorusu 1: Cep telefonunuzda kullandiğınız herhangi bir hava durumu uygulaması var mı? Varsa lütfen adını belirtiniz.

$\mathrm{Bu}$ soruya verilen yanıtlar incelendiğinde, 53 öğretmen adayının çeşitli hava durumu uygulamalarını kullandıkları görülmüştür. 25 öğretmen adayı AccuWeather adlı uygulamayı, 11 ögretmen adayı Google Hava Durumu uygulamasını, 4 öğretmen adayı The Weather Channel uygulamasını ve 2 öğretmen adayı Meteoroloji adlı uygulamayı kullandıklarını belirtmiştir. 11 ögretmen adayı ise herhangi bir ek program kullanmadıklarını, cep telefonlarında var olan programı kullandıklarını ifade etmişlerdir. 11 öğretmen adayı ise herhangi bir hava durumu uygulamasını kullanmadıklarını açıklamıştır.

Görüşme Sorusu 2: Hava durumu uygulamanızı ya da meteoroloji haberlerini hangi siklikta takip edersiniz?

Öğretmen adaylarının hava durumu haberlerini takip etme sıklıkları periyodik aralıklarla takip edenler ve belirli bir koşula bağlı olarak takip edenler olmak üzere iki tema oluşturmuştur. Periyodik aralıklarla takip edenler teması altında düzenli takip edenler ve düzensiz takip edenler olmak üzere iki kod bulunmaktadır. Düzensiz takip eden katılımcılar teması altında toplanan yanıtların genellikle nadiren takip etme noktasında birleştiği görülmüştür. Düzenli takip eden katılımcıların çoğunluğunun ise meteoroloji haberlerini çeşitli kaynaklardan her gün takip ettiklerini belirttikleri tespit edilmiştir. Belirli bir koşula bağlı olarak takip edenler teması ise plan ve haber bülteni olmak üzere iki kod barındırmaktadır. Bununla birlikte, 5 öğretmen adayı hava durumuna ilişkin haberleri hiç takip etmediklerini belirtmişlerdir. Söz konusu katılımcılar, "Takip etme ihtiyacı hissetmiyorum ve bu nedenle de hiç bakmam." ve "Hiç takip etmem." örnekleriyle benzer yanıtları vermişlerdir.

Tablo 2. Öğretmen adaylarının hava durumunu takip etme durumları

\begin{tabular}{lc}
\hline & $\mathrm{f}$ \\
\hline Periyodik aralıklarla takip edenler & \\
Düzensiz takip edenler & 14 \\
Düzenli takip edenler & 37 \\
\hline Belirli bir koşula bağlı olarak takip edenler & \\
Plan & 6 \\
Haber bülteni & 2 \\
\hline
\end{tabular}

Periyodik aralıklarla takip edenler temasını oluşturan yanıtlar incelendiğinde, düzensiz takip eden öğretmen adaylarının yanıtları "Ara sıra, haftada 1 ya da 2 kere..." şeklindedir. Düzenli takip edenler kodu altında birleşen yanıtlara ilişkin örnekler ise şu şekildedir:

"Her sabah uyandığımda günlük hava sıcaklığına bakarım."

"Telefonu elime aldığımda bakacağım ilk uygulama hava durumu uygulamasıdır." 
"Haftalık ve günlük hava durumu olarak her gün takip ediyorum."

"Günlük bakarım. Çünkü ona göre giyinirim."

"Genel itibari ile günlük bakarım. Özellikle uyumadan önce yarınki hava durumuna bakarım."

Belirli bir koşula bağlı olarak takip edenler teması altında bulunan plan kodunu oluşturan yanıtlar, öğretmen adaylarının takvimlerinde bulunan etkinliklere göre hava durumu haberlerini takip ettiklerini belirten açıklamalar üzerine kurulmuştur. Bu bölüme ilişkin örnekler şu şekildedir:

"Bir yere seyahat edeceğim zaman telefondan ya da internetten bakarım. Bir de köyde bitkilerle uğraştı̆̆ım zamanlarda takip ediyorum."

"Hava durumu uygulamasına gitmem gereken önemli bir yer olduğunda bakıyorum."

"Tarım işleri yapacağım zaman, yani ekim dikim zamanlarında bakarım. Yolculuğa ya da geziye gideceğim zamanlarda da hep bakarım."

"Hava kapalı olduğu zaman dışarı çıkacaksam bakarım. Yağmur olup olmadığını kontrol edip şemsiye vs. alıyorum yanıma."

Haber bülteni kodu, öğretmen adaylarının haber bültenleri sonlarındaki hava durumu haberlerini takip etmelerine ilişkin açıklamalarını kapsamaktadır. Bu koda ilişkin örnekler aşağıda sunulmaktadır:

"Haberlerin hemen arkasında denk gelirsem öğreniyorum hava durumunu."

"Genelde haberlerden sonra, hava durumunu takip ederim."

Görüşme Sorusu 3: Hava tahminlerinden edindiğiniz açıklamalara inanma düzeyiniz hakkında bilgi veriniz.

Katılımcıların bu konudaki açıklamaları doğrultusunda kesinlikle inanmayanlar, nadiren inananlar, orta düzeyde inanlar, çoğunlukla inananlar ve kesinlikle inanlar olmak üzere beş kod oluşmuştur. Hava tahminlerine ilişkin haberleri takip etmediklerini belirten katılımcılar $(n=5)$, bu konudaki verilere kesinlikle inanmadıklarını belirtmişlerdir. Bu durumun yanı sıra, hava durumu haberlerini nadiren takip ettiğini belirten 1 katılımc1 da bu görüşü desteklemiştir. Katılımcı yanıtlarına ilişkin örnekler şu şekildedir:

"Zaten hiçbir şekilde inanmadığım için hava durumu haberlerini takip etmiyorum."

"Bence doğru çıkmıyor bu haberler. Ben o nedenle hiç inanmam ve açıp bakmam."

5 katılımcı hava tahminlerine nadiren inandıklarını ifade etmiştir. Bu görüşe yönelik örnekler aşağıdaki gibidir:

"Haberler ve uygulamadaki değerler teknik veriler ile saptanıyor. Ancak bağıl nem ile değişiklik gösteriyor mesela. O nedenle tam anlamı ile kabullenmem. Yani ara sıra inanırım diyebilirim."

"Çok az inanıyorum. 5 üzerinden 1 verebilirim inanma düzeyime."

"Birebir inanmıyorum. Çünkü çoğu zaman yanlış tahminlerde bulunabiliyor. Yine de yaklaşık değerler verdiği için bilgi ediniyorum. Ama sonuç olarak çok az inanıyorum."

9 katılımcı, edindikleri hava tahmini verilerine $\% 50$ oranında inandığını belirtmiştir. Bu grupta yer alan katılımcı açıklamalarına ilişkin örnekler aşağıda sunulmaktadır:

"Meteoroloji değişebilen bir tahmin olayı olduğu için \%50."

"Saatlik olarak değiştiği için uzun zaman dağılımında çok güvenmiyorum. Günlük ya da saatlik tahmini daha güvenilir. Yani yarı yarıya inanıyorum."

"illk önce telefon hava durumuna baktıktan sonra gökyüzüne bakarım. Bulutlu mu, güneşli mi, vs. diye. Yani \%50 inanırım."

Çoğunlukla inandığını belirten katılımcı yanıtlarına $(\mathrm{n}=38)$ yönelik örnekler şu şekildedir:

"Meteoroloji haberlerine \%90 inanıyorum. Çünkü teknoloji gelişti ve doğru sonuçlar veriyor." 
"Hava durumuna güvenirim, ama bu yüzde yüz olmaz. Bazı zamanlar da yanıldığım da olmuştur. Yağmurlu gösterilip de güneşli günler görülebiliyor. Ama büyük çoğunlukla da inanıyorum hava tahminlerine."

“\%70, çünkü bazen gösterdiği saatlerde ve günlerde hava durumu aynı olmuyor. Fakat bu çok nadir. O nedenle genellikle inanıyorum."

"Çoğu zaman inanıyorum, ama ara ara sürpriz yapıp yağmurlu gösteren havada güneşli bir havayla karşılaşabiliyorum."

6 katılımcı ise hava tahminlerinden elde ettikleri bilgilere kesinlikle inandığını ifade etmiş̧ir. Bu görüşü destekleyen katılımcı yanıtlarına ilişkin örnekler aşağıda sunulmaktadır:

"Ben her zaman inanırım ve ona göre giyinirim. Şemsiye, mont vs. kullanıp kullanmayacağıma öyle karar veririm."

"Meteoroloji haberlerine ve hava durumu uygulaması haberlerine kesinlikle inanıorum. Bence hep doğru çıkıyor."

Görüşme Sorusu 4: Hava tahminleri aracıliğlyla edindiğiniz bilgileri, gün içerisinde karşılaştığınız hava koşulları ile kıyaslar mısınız?

$\mathrm{Bu}$ soruya verilen katılımc1 yanitları kesinlikle kıyaslamayanlar, bazen kıyaslayanlar, çoğunlukla kıyaslayanlar ve kesinlikle kıyaslayanlar olmak üzere 4 farklı kod altında toplanmıştır. 11 katılımcı, hava tahmini verileri ile günlük yaşamlarında karşılaştıkları hava durumunu kesinlikle kıyaslamadığını belirtmiştir. Bunun yanı sıra, hava tahmini verilerini takip etmediğini belirten 5 katılımcıdan 2'si geçmiş kıyaslamalarının tutarsız sonuçlarından dolayı hava durumu uygulamalarını ve haberlerini takip etmeyi bıraktıklarını açıklamıştır. Kesinlikle kıyaslama yapmadığını belirten katılımcı yanıtlarına örnekler şu şekildedir:

"Ben hiç kıyaslamam. Açıkçası aklıma bile gelmez kıyaslama yapmak."

"Nadiren takip ettiğim için kıyaslama da yapmıyorum. Yani, hiç hatırlamıyorum kıyaslama yaptığımı."

9 katılımcı, edindiği veriler ile gün içerisinde karşılaştığı hava durumunu bazen kıyasladığını açıklamıştır. Bu görüşe ilişkin örnekler aşağıdaki gibidir:

"Eğer hava durumuna göre hareket ettiysem yani şemsiye almak gibi, öyle zamanlarda özellikle dikkat ederim. Bu da çok sık olan bir şey değil."

"Bazen telefonun gösterdiği sıcaklık, gün içinde daha fazla soğuk olduğu zaman bakarım."

Hava tahmini verileri ile gün içerisindeki hava durumu arasında çoğunlukla karşılaştırma yaptığını belirten katılımcı $(\mathrm{n}=29)$ görüşlerine örnekler aşağıda sunulmaktadır:

"Genellikle kıyaslarım. Bazen yanlış bilgi verildiği oluyor. Kesin sonuç vermiyor."

"Dışarı çıkmadan önce uygulamadan bakarım. Çıktıktan sonra da uygulama ile çoğu zaman kıyaslarım."

"Kıyaslarım. Özellikle yağmur veya kar yağışı olacağı zaman daha çok dikkat ederim."

Hava tahminleri aracılığıyla edindiği bilgileri, gün içerisindeki hava koşulları ile kesinlikle kıyasladığını ifade eden katılımcı $(\mathrm{n}=10)$ yanıtlarına yönelik örnekler şu şekildedir:

"Ben her gün kıyaslarım. Örnek verecek olursam bugün telefonun uygulamasında hava durumu sabahtan akşama kadar yağmurlu gösteriyordu. Ona göre kalın giyindim, ama şuan hava güneşli ve sicak."

"Kesinlikle kıyaslarım. Genel gözlemime göre bahar aylarında yağmur yağabilecek saatler uyumsuz oluyor."

"Her zaman kıyaslama yaparım. En çok da ilkbahar ve sonbahar dönemlerinde uyuşmazlık oluyor."

Görüşme Sorusu 5: Meteorolojik halk takvimi denildiğinde ne anllyorsunuz?

$\mathrm{Bu}$ soruya verilen yanıtlar incelendiğinde, 9 katılımcının meteorolojik halk takvimi konusunda herhangi bir bilgisinin olmadığ 1 görülmüştür. 12 katılımcı ise bu ifade ile kamuya duyurulan hava tahmini verilerinin kastedildiğini belirtmiştir. Bu durumun yanı sıra, 43 katılımcı 
meteorolojik halk takvimini tahmine dayalı ve gözleme dayalı olmak üzere iki farklı kod altında incelemiştir.

Meteorolojik halk takviminin tahmine dayalı olduğunu ifade eden katılımcılar $(n=23)$, genel olarak söz konusu takvimin günlük ya da anlık olarak hava durumunun tahmin edilmesi ile elde edildiğini açıklamıştır. Bununla birlikte, 6 katılımcı bu takvimin bilimsel olmadığını ifade etmiştir. Katılımcıların yanıtlarına örnekler aşağıda sunulmaktadır:

"Meteorolojik halk takvimi insanların hava tahminleridir. Bilimselliği olmadığını ve belirli bir derece vermediğini düşünüyorum. Yani bulutlu, güneşli şeklinde olabilir. $12^{\circ} \mathrm{C}$ gibi belirli dereceler verilemez."

"İnsanların hava durumu haberlerine bakmadan anlık ya da diğer güne yaptıkları tahminlerdir."

Meteorolojik halk takviminin gözleme dayalı olduğunu ifade eden katılımcılar $(\mathrm{n}=20)$ açıklamalarını yaparken deneyim ve çalışma alanı gibi konulara odaklanarak bu takvimin uzun süreli gözlemlere dayandığını ifade etmiştir. Bu görüşe ilişkin yanıt örnekleri şu şekildedir:

"İnsanların yüzyıllar boyunca hava hareketlerine, zamanlarına bakarak oluşturdukları takvimdir. Bildiğim kadarıyla eskiden koca karı takvimi diye adlandırılırdı ve fırtına takvimi olarak da biliniyor sanırım."

"İnsanların geçmişten itibaren günleri izleyerek oluşturdukları takvimdir. Mevsimlerde meydana gelecek hadiseleri gözlemleri sonucu takvime aktarmışlardır. Yani, tecrübe sonucu elde edilmiş, her yıl aynı zamanlarda gerçekleşen olayların halk tarafından kaydedilmesi ve bilinmesidir."

"İnsanlar eskiden çoğunlukla tarım ile ilgilendiklerinden ekme, biçme zamanlarını kendilerine göre bir takvim oluşturarak yapmışlardır. Büyüklerimizin hayat deneyimlerinden yola çıkarak oluşturdukları takvimdir. Örneğin, cemre düşmesi, arap ayı, fakir yazı gibi tabirler..."

Görüşme Sorusu 6: Pastırma sıcakları, koca karı soğukları gibi hava koşulları hakkındaki düşüncelerinizi lütfen açılklayınız.

4 katılımcı söz konusu ifadeleri daha önce hiç duymadıklarını belirterek bu konuda herhangi bir fikirleri olmadığını açıklamıştır. Bunun yanı sıra, 60 katılımcılının bu soruya ilişkin cevapları bu tür kavramların bilimsel olması, bilimsel olmaması ve bilimselliğe yakın olması şeklinde değerlendirdiği görülmüştür. Bu noktada, 33 öğretmen adayı bu kavramların gözleme dayandığı için bilimsel alt yapısı olduğunu ifade etmiştir. 22 öğretmen adayı ise söz konusu ifadelerin bilimle herhangi bir ilgisi olmadığını ve bu gibi ifadelerin oluşumunda bilimsel yöntemlerin kullanılmadığını belirtmiştir. 9 öğretmen adayı bu ifadelerin tamamen bilimsel süreçleri içermese de benzer aşamalar izleyebileceğini açıklayarak bu kavramların bilimselliğe yakın olduğunu düşündüklerini bildirmişlerdir. Katılımcı cevaplarına ilişkin örnekler aşağıda sunulmaktadır:

“... Bu ifadeler gözlem sonucu edinilmiş bilgilerdir. Yani, çok sıcak olduğu için pastırma sıcakları denmiştir ya da çok soğuk havalar yaşlı insanların o buz gibi tavırlarına benzetilmiştir. İnsanlar bu havaları tanımlamak için akılda kalıcı tabirler kullanırlar. Yani bunlar da gözlemle olduğu için bilimsel olduğunu düşünüyorum bu olayların..."

"Bence bu kavramların doğruluğu yoktur. Yani sadece kültürle ilgili şeylerdir bunlar. İnsanların dilinden diline kültürümüze yansımış benzetmelerdir. O nedenle de bunların bilimle, yani bilimsel aşamalarla alakası yoktur. Sonuçta deney falan yapmadan sadece kültürle oluşan şeyler..."

"Çok duyduğum kelimeler bunlar. Anneannem falan çok kullanır yani. Herhalde atalarımızın halk arasında kullandığı meteorolojik bir açıklama gibi bunlar. Yalnız, insanların gece gökyüzüne bakıp kapalı, sık ve hareketli bulutları görünce koca karı soğukları geliyor denilmesi gibi şeyler hatırlıyorum... Yani insanlar bu hava olaylarını uzun süre gözlemleri sonucu ortaya koyduğu için tutarlılığı olduğunu düşünüyorum. Bilimsel olabilir bunlar bana göre, ama çok da emin değilim..." 


\subsection{Meteoroloji Gözlem Etkinliği Sonrasındaki Görüşme Bulguları}

Görüşme Sorusu 1: Hava durumu uygulamanızdan kaydetmiş olduğunuz haftalık veriler ve günlük veriler ile gün içerisinde yaşadı̆̆ınız hava koşullarının benzerlik gösterme/göstermeme durumu hakkında bilgi veriniz.

$\mathrm{Bu}$ soruya verilen yanıtlar incelendiğinde, katılımcıların genel olarak haftalık veriler ile günlük veriler arasında farklılık olduğunu ve haftalık verilerin günlük verilere nazaran daha çok değiştiğini belirttikleri görülmüştür. Günlük verilerin doğruluk oranının haftalık verilere göre daha yüksek olması ile birlikte bu verilerde de tutarsızliklar gözlemlediklerini belirtmişlerdir. Bununla birlikte, belirli bir tarih için elde edilen önceki sonuçların hızlı bir şekilde değișebildiğini ve bu noktada birçok değişken olduğunu ifade eden katılımcıların gözlem koşullarına da sıklıkla vurgu yaptıkları görülmüştür. Katılımcı yanıtlarına ilişkin örnekler aşağıda sunulmaktadır:

"Haftalık ve günlük benzerlik birbirine yakın olsa da bazı günler benzerlik sağlanmadı. Güneşli gösterdiği halde yağmur yağdı mesela... Günlük veriler genellikle benzerlik gösterdi ama son ayda saatlik veri bile değişti bir saat içinde. Hem güneşli oldu hem yağışlı oldu yani peş peşe..."

"Hava durumları günlük yapılınca daha kesin sonuçlara ulaşıyoruz. Yani günlük olan daha çok benzerlik gösteriyor. Ama benim bu süreçte haftalık ve gün içerisinde kendi yapmış olduğum hava tahminleri de çoğunlukla tutmadı. Çünkü hava olayları günlük gerçekleşen olaylardır. Özellikle bir günden fazla yapılanlar artık hava durumu değil de iklime girer yani..."

"Ben günlük verilere daha çok güveniyorum. Çünkü bu veriler gün içerisinde karşılaştığım hava durumları ile birbirine daha yakındı. Ama bazen uyuşmadığı zamanlar da oldu. Öğlen sıcak gösterirken yağmur yağdı... Böyle istisnai durumlar olsa da genel olarak birbirine yakın veriler elde ettim. Ama haftalık verilerle günlük verilerim birbirini tutmadı. Bazı zamanlarda birbirine yakındı, hatta aynı olduğu veriler de geldi fakat çoğu zaman birbirini tutmadı... Ama böyle olması da normal bence, yani sonuçta hava durumunu etkileyen bir sürü şey var. Bir de üstüne gözlem yapılan yerin şartları da değişiyor. Yani, o nedenle bu tutarsızlıkların olması bence çok normaldi..."

Görüşme Sorusu 2: Uygulamanın sunmuş olduğu veriler ile yaşamış olduğunuz hava koşulları arasındaki uyuşmazlıkların nedenlerini tartışınız.

Katılımc1 yanıtları incelendiğinde, genel olarak bilimsel bilginin niteliklerine odaklanıldığ görülmektedir. Bu noktada, bilimsel bilginin gözleme dayandığının ve bu nedenle sıklıkla değişebilir olduğunun vurgulandığ 1 görülmüştür.

"Gözlemlerde mutlak doğru yoktur... Gözlemde hatalar da vardır. Uygulama her zaman doğru olacak diye bir şey yoktur. Gözlemleri teorilere benzetebiliriz. Teoriler de değişebilir, sınanabilir, farklılıklar olabilir. Hava olaylarının farklı olması, uyuşmazlık olması buna benziyor. Mesela deneylerde yaptığımız gözlemlerde de farklılıklar oluyordu... Yani bilimsel bilgiler zamanla değişebilir, bir şeyler eklenebilir veya çıkarılabilir. Hava durumunda da aynı şekilde kesin olarak bir şey diyemeyiz. $\mathrm{O}$ gün hava durumuna baktığımızda mesela $10^{\circ} \mathrm{C}$ gösteriyor diye biz buna kesin doğrudur diyemeyiz. Bilimde nasıl bir kesinlik yoksa bu da bir bilim olduğu için kesinlik yoktur..."

"Verilen bilginin ya da öğrenilen bilginin araştırılıp gözlem yapılması ve kıyaslanması sonucu doğruluğuna karar verilir. Bilgiler zamanla değişebilir. Örneğin, atomun parçalanamayacağ söyleniyordu. Fakat teknoloji ilerledikçe bunun mümkün olduğu ortaya çıkmıştır. Yani kesin diye bir şey yoktur. Hava durumu da buna dâhildir. Önceden baktığımız hava durumu o güne gelince hatta bazı saatlerde bile farklılık göstermiştir. Bir fenci duyduklarına hemen inanmamalıdır. Araştırıp gözlem yapıp doğruluğunu test etmelidir..."

Her bir katılımcının uygulama verilerini ve hissedilen hava durumunu içeren çizelgeleri aracılığıyla yapmış oldukları karşılaştırmaları sonucunda elde ettikleri uyuşmazlıkları değişen dünya ve gözlem koşulları olmak üzere iki sınıfta inceledikleri görülmüştür. Değişen dünya teması iklim değişikliği, küresel ısınma, sera etkisi, atmosferin incelmesi, çevre kirliliği ve ozon tabakasının incelmesi olmak üzere 6 farklı kod içermektedir. Bununla birlikte, gözlem koşulları teması kapsamında ani değişimler, hata payı ve uygun ortam şeklinde listelenen 3 kod bulunmaktadır. 
Tablo 3. Öğretmen adaylarının belirledikleri uyuşmazlıklar hakkındaki görüşleri

\begin{tabular}{lc} 
& $\mathrm{f}$ \\
\hline Değişen Dünya & \\
İklim değişikliği & 28 \\
Küresel ısınma & 19 \\
Sera etkisi & 14 \\
Atmosferin incelmesi & 11 \\
Çevre kirliliği & 7 \\
Ozon tabakasının incelmesi & 5 \\
\hline Gözlem Koşulları & \\
Ani değişimler & 28 \\
Hata payi & 16 \\
Uygun ortam & 8 \\
\hline
\end{tabular}

Değişen dünya teması kapsamında sonuçları tartışan katılımcıların uygulama verileri ile hissedilen hava durumu arasındaki uyuşmazlıkların nedeni olarak iklim değişikliği, küresel 1sınma, sera etkisi, atmosferin incelmesi, çevre kirliliği ve ozon tabakasının incelmesi konularına değinmiştir. Katılımcılar fabrika bacalarını, egzoz gazlarını ve insanların doğaya zarar vermesini örnek olarak göstermiştir. Katılımcılar bu olayların iklim üzerindeki etkisini vurgulamış ve dünya genelinde değişimlere yol açtığını ifade etmiştir.

Gözlem koşulları temasında gökyüzünde gerçekleşen ani değişimlerin söz konusu uyuşmazlıklar üzerinde etkili olduğunu ifade eden katılımcılar, özellikle beklenmedik bir şekilde ortaya çıkan rüzgâr ve firtınaların hava durumu için önemli faktörler olduğunu belirtmiştir. Bununla birlikte, bilimsel verilerin elde edilmesi aşamasında her zaman hata payı bulunabileceğini ve bu nedenle ölçümlerin genellikle birçok kez tekrarlandığını ifade etmişlerdir. Ayrıca, gözlem yapılması için uygun ortam koşullarına gereksinim duyulduğunu açıklamışlardır. Örneğin, bulutlu bir havada gözlem yapmanın zor olduğunu ifade eden katılımcılar $(n=5)$, bu durumun yağmur beklentisi yönünde yanlış bir yoruma neden olabileceğini belirttikleri görülmüştür.

\subsection{Doküman İncelemesi}

Bu aşamada, meteoroloji gözlem etkinliği sürecinde her bir öğretmen adayının hazırlamış olduğu gözlem kayıt çizelgeleri incelenmiştir. Çizelgeler incelendiğinde, genel olarak elde edilen haftalık veriler ile günlük veriler arasında farklılıklar olduğu görülmüştür. Özellikle bazı günlerde bu farklılığın oldukça yüksek olduğu dikkat çekmiştir. Örneğin, Şekil 1'de sunulan bir kayıt çizelgesi kesitinin 7. gözlem gününde haftalık veri sabah saatleri için "güneşli ve $4^{\circ} \mathrm{C}$ " iken günlük verinin "parçalı bulutlu ve $17^{\circ} \mathrm{C}$ ” olduğu görülmüştür. Bununla birlikte, veriler arasındaki tutarsızlıkların azaldığı gözlem sonuçları da bulunmaktadır. Bu sonuçlarda, genel olarak haftalık ve günlük veriler arasında birkaç santigrat derecelik farklar bulunduğu görülmüştür. Örneğin, Şekil 1'deki kayıt çizelgesi kesitinde 1. gözlem gününde haftalık uygulama verisi öğle saatleri için "parçalı bulutlu ve $12^{\circ} \mathrm{C}$ " şeklinde belirtilmiş ve bu aralık günlük verilerde "parçalı bulutlu ve $10^{\circ} \mathrm{C}$ " olarak açıklanmıştır. Gözlem kayıt çizelgeleri incelendiğinde, hissedilen hava durumunun genel olarak günlük hava durumu verileri ile daha çok uyum içerisinde olduğu ifade edilebilir. 


\begin{tabular}{|c|c|c|c|c|c|c|c|c|c|c|}
\hline \multirow{2}{*}{ Gün } & \multicolumn{3}{|c|}{ Uygulamamin Haftalık Hava Durumu } & \multicolumn{3}{|c|}{ Hissettiğiniz Hava Durumu } & \multicolumn{3}{|c|}{ Uygulamanin Günlük Hava Durumu } & \multirow[b]{2}{*}{ 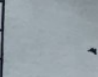 } \\
\hline & Sabah & Öğlen & Akşam & Sabah & Öğlen & Akssam & Sabah & Oglen & Akşam & \\
\hline 15.03 .2018 & 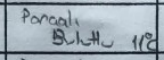 & \begin{tabular}{|} 
Poraal \\
Buluth, 12C
\end{tabular} & $\begin{array}{r}B_{0}+10+1 \\
100 \mathrm{C}\end{array}$ & Buthe & Pargali, Buth. & Yağmurl, & 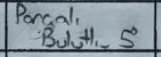 & \begin{tabular}{|} 
Porcal \\
Bistill $10^{\circ}$
\end{tabular} & Bulth, ${ }^{\circ}$ & \\
\hline 16.03 .2018 & $\begin{array}{l}\text { Poraali } \\
\text { Busti, } 0^{\circ} \mathrm{C}\end{array}$ & $\begin{array}{l}\text { Paraal, } \\
\text { Bulith, } 110 \mathrm{C}\end{array}$ & \begin{tabular}{|l|} 
Poraali \\
Bul, $10^{\circ} \mathrm{C}$
\end{tabular} & Buston & Parápilit. & $\begin{array}{l}\text { Porag. } \\
\text { Bu. }\end{array}$ & \begin{tabular}{|c|} 
Por cali \\
Pulitle i i
\end{tabular} & Gineşो $16^{\circ}$ & $\begin{array}{l}\text { Poracil } \\
\text { Bulutiv } 10^{\circ}\end{array}$ & \\
\hline 17.03 .2018 & $\begin{array}{l}\text { Poracal, bulisth } \\
5^{\circ} \mathrm{C}\end{array}$ & Gines $16^{\circ} \mathrm{C}$ & $\begin{array}{l}\text { Porach } \\
\text { B.jll, is C }\end{array}$ & But th & $\begin{array}{r}\text { Porcali: } \\
\text { But }\end{array}$ & Bulftll, & 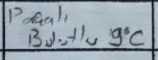 & $\begin{array}{l}\text { Gogsiuklo } \\
\text { Ginesli laC }\end{array}$ & $\begin{array}{r}\text { Cokbuluth } \\
13^{\circ} \mathrm{C}\end{array}$ & \\
\hline 18.03 .2018 & $\begin{array}{l}\text { Poraal } \\
\text { Bustl, } 7^{\circ}\end{array}$ & Gores: $22^{\circ}$ & $\begin{array}{l}\text { Percali } \\
\text { Buli, } 19^{\circ} \mathrm{C}\end{array}$ & Bulut I & Poraglinith & Bustin & Gins sli $B^{\circ}$ & Poraglit I 208 & $\begin{array}{l}\text { Gok } \\
3,4,4,180 \mathrm{C}\end{array}$ & \\
\hline 19.03.2018 & 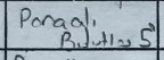 & Girest: & 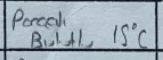 & Butles & Porcalibti. & Bul.t., & Bu both $10^{\circ} \mathrm{C}$ & Busthe $15^{\circ}$ & $B u+1+1+13^{2} \mathrm{C}$ & \\
\hline 20.03.2018 & Buluth $4^{\circ}$ & Ginesli $18^{\circ}$ & Perciallith $15^{\circ} \mathrm{C}$ & Buluth & Bulutb & $B u+t_{1-1}$ & Aaik $4^{\circ} \mathrm{C}$ & Bas, ${ }^{3}+1 / 4 R^{\circ} \mathrm{C}$ & $\begin{array}{r}\text { cok buls } \\
16^{\circ} \mathrm{C} \\
\end{array}$ & \\
\hline 21.03 .2018 & Ginesli $4^{\circ}$ & Ginest: $16^{\circ} \mathrm{C}$ & 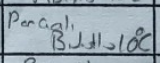 & Bu/vtl, & Preaclíl & Paraal & $\begin{array}{c}\text { Ponadi Bully } \\
1^{\circ}\end{array}$ & $\begin{array}{c}\text { Preall Butull } \\
22^{\circ}\end{array}$ & Percalihuthl. & \\
\hline 22.03 .2018 & Buluth $5^{\circ}$ & $\begin{array}{c}\text { Bul., } 1 \text { 11? } \\
14^{\circ}\end{array}$ & Bish, li, $10^{\circ} \mathrm{C}$ & Buth, & Ginesli & Perachis d, inth & \begin{tabular}{|c|} 
Praal, $B_{1}, y^{\circ}$ \\
$\mid 5^{\circ}$
\end{tabular} & $\begin{array}{c}\text { Porali } \text { Bubly } \\
20\end{array}$ & buts. & \\
\hline 23.03 .2018 & \begin{tabular}{|} 
Poraal, B.J otll| \\
$g^{\circ} \mathrm{C}$
\end{tabular} & $\begin{array}{r}\text { Penali Boldh } \\
2 u^{\circ} \mathrm{C} \\
\end{array}$ & 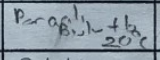 & B.juthe & Ris zgorli & Rilzgarl & P., sL Gines! & Buth $22^{\circ} \mathrm{C}$ & $\begin{array}{c}\text { Cok B.lutic } \\
20^{\circ} \mathrm{C}\end{array}$ & \\
\hline 24.03 .2018 & Bust 1. $2^{\circ}$ & Haf: fongmung & Bul, $+1,10^{\circ} \mathrm{C}$ & $3 \mathrm{~B}_{2} \mathrm{gON}_{1}$ & Jaḡmarle & Yasmu-rl & Gines $118^{\circ} \mathrm{C}$ & $\begin{array}{r}\alpha \text { at Bunth } \\
150\end{array}$ & $\begin{array}{r}\operatorname{Cok} B_{3} 1.112 \\
12\end{array}$ & \\
\hline 25.03 .2018 & $\begin{array}{r}\text { Buloth } \\
2^{\circ}\end{array}$ & Par Ballitu $1 \mathrm{BS}^{\circ} \mathrm{C}$ & Bubth $10^{\circ} \mathrm{C}$ & Buloth & $\begin{array}{c}\text { Peracal } \\
\text { Bisluth }\end{array}$ & Bu, intiv & 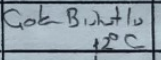 & $\begin{array}{c}\text { Cok buluth } \\
15^{5} \mathrm{C}\end{array}$ & $\begin{array}{c}\text { fiok bujt: } \\
g^{\circ} \mathrm{C}^{-1}\end{array}$ & \\
\hline 26.03 .2018 & Boluth so & \begin{tabular}{|c|} 
Porali, \\
Buluti,
\end{tabular} & $\begin{array}{l}\text { Pracal } \\
\text { Bul, the } 15^{\circ} \mathrm{C} \\
\end{array}$ & B, $2+h$ & Bubto & B, lo, the & 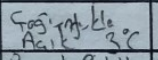 & 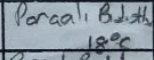 & Gok B d L 14 , & \\
\hline 27.03 .2018 & 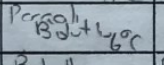 & Gires li ${ }^{\circ} \mathrm{c}$ & $\begin{array}{r}\text { Peraak Bultt } \\
15^{\circ} \mathrm{C}\end{array}$ & $3,1,+1$, & Paraglitulu, & $\begin{array}{c}\text { Pcraal } \\
\text { Beluthe, }\end{array}$ & 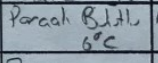 & U. & 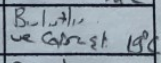 & 9 \\
\hline 28.03.2018 & B.duth 60 & $\begin{array}{r}B u+1 w \\
A^{\circ} \mathrm{C}\end{array}$ & Busthic $16^{\circ} \mathrm{C}$ & $\begin{array}{l}\text { Poracel, } \\
\text { Bulu+1 }\end{array}$ & G: & Bustl. & $\left.B_{1}\right)$ & B.ht ${ }_{2} \mathrm{rC}_{\mathrm{C}}$ & B.Luth & $91 \%$ \\
\hline 29.03 .2018 & Yagm, s. & $\begin{array}{r}\text { zagm.n/2 } \\
166^{\circ} \mathrm{C}\end{array}$ & $\begin{array}{c}\text { Yagmint } \\
1 L^{\circ} \mathrm{C}\end{array}$ & Yasmurl. & $\begin{array}{c}\text { Pargal' } \\
\text { Bosulutiu }\end{array}$ & Jas̄munte & $\begin{array}{r}\text { Saganak } \\
\text { ang }\end{array}$ & $\begin{array}{l}B_{10} 0^{\circ} \mathrm{C} \\
0\end{array}$ & $\begin{array}{l}\text { Sasenak } \\
\text { yağ's \&C }\end{array}$ & $75 \%$ \\
\hline 30.03 .2018 & Bustle we & $\begin{array}{l}\text { Poraal. } \\
\text { Bulutl-110 }\end{array}$ & Bulut ${ }^{\circ} \mathrm{C}$ & Yaḡmuli, & $B w_{1}-H_{1}$ & Buhtli, & thif & & & $3 \%$ \\
\hline 31.03 .2018 & \begin{tabular}{|c|} 
Peraal, Buth \\
\end{tabular} & Ginest: $17^{\circ} \mathrm{C}$ & aine हो 15 & ParacliBjot $h_{2}$ & Gines: & Ginesl: & Dratibutis & $\begin{array}{r}\text { Rismen Githes! } \\
15^{8} \mathrm{C} \\
\end{array}$ & $\begin{array}{c}\text { Yer Ye Bulth } \\
\text { Boc }\end{array}$ & $\%$ \\
\hline 01.04 .2018 & 10 & $\begin{array}{c}\text { Pacal Bulatl. } \\
21^{\circ} \mathrm{C}\end{array}$ & $\begin{array}{l}\text { Paraal } \\
\text { But }+1+2 e\end{array}$ & $P_{\text {craali }} B_{y_{1}}$ th & Ginesk & Paragaliut & $\begin{array}{c}\text { Poraal bu } \\
70\end{array}$ & 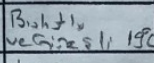 & $\begin{array}{l}\text { Poraal } \\
\text { Buht } 120 \mathrm{C}\end{array}$ & $1 \%$ \\
\hline 02.04 .2018 & 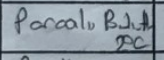 & Givere $18^{\circ} \mathrm{C}$ & 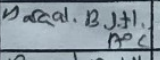 & $\begin{array}{c}\text { Paranali } \\
\text { pusutiv }\end{array}$ & Yas̄mul & & 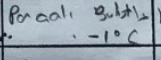 & Hafiryagis fCC & $\begin{array}{l}\text { Paraal } \\
\text { Buhth, } 8 \mathrm{C}\end{array}$ & $3 \%$ \\
\hline 03.04 .2018 & ${ }^{B d u t h}=C$ & Ginest $16^{\circ} \mathrm{C}$ & $\begin{array}{r}\text { Praal. Bu, litt } \\
15^{\circ} \mathrm{C}\end{array}$ & $\begin{array}{l}\text { Porali } \\
\text { Bult L }\end{array}$ & $\begin{array}{l}\text { Perari itio } \\
\text { Bulistis }\end{array}$ & Peracaliotl. & Gincest: $6^{\circ} \mathrm{C}$ & Gionesli 1 lic & $\begin{array}{l}\text { Gogniska } \\
\text { Aalk } 10^{\circ} \mathrm{C}\end{array}$ & $0 \%$ \\
\hline 04.04 .2018 & $\begin{array}{r}\text { Parco } \\
\text { Bin }\end{array}$ & Givesli $16^{\circ} \mathrm{C}$ & Ginesl: & Gimast: & Gumas li & Giones!! & Aalk & Gives: & Aark & \\
\hline
\end{tabular}

Şekil 1. Gözlem çizelgesi örneği

\section{TARTIŞMA ve SONUÇ}

$\mathrm{Bu}$ çalışmanın amacı fen bilgisi öğretmen adaylarının gözlem yapmalarını ve yaptıkları gözlemler aracılı̆̆ıyla hava durumuna ve bilimsel bilginin niteliklerine ilişkin çıkarımlarda bulunmalarını sağlamak şeklinde belirlenmiştir. Bu amaç doğrultusunda, 11 haftalık meteoroloji gözlem etkinliği düzenlenmiş̧ir. Okul dişı etkinlik olarak planlanan bu süreçte, öğretmen adayları çeşitli mobil uygulamaları kullanarak edindikleri hava durumu verilerini ve duyu organları aracılığıyla algıladıkları hava koşullarını kaydetmişlerdir. Gözlem kayıtlarını oluşturma sürecinde üç aşama takip edilmiştir. Öğretmen adayları öncelikle mobil uygulamanın sunduğu haftalık hava durumu verilerini takip eden hafta için kaydetmiştir. Söz konusu hafta içerisinde, uygulamaya ait günlük hava durumu verileri her gün tekrar okunarak gözlem kayıt çizelgesine eklenmiştir. Aynı zamanda bu süreçte, karşılaştıkları ve hissettikleri hava durumu koşullarını çizelgelerine kaydetmişlerdir. Bu süreçte, tüm kayıtlar sabah, öğle ve akşam saatleri olmak üzere günde üç kez incelenmiştir. Öğretmen adayları bu süreç kapsamında çizelgelerindeki verileri karşılaştırmış ve değerlendirme yapmıştır.

Araştırmanın birinci problemini değerlendirmek amacıyla meteoroloji gözlem etkinliği öncesinde gerçekleştirilen görüşme verileri incelenmiştir. Çoğu öğretmen adayı $(n=53)$, hava durumu hakkında bilgi sunan çeşitli mobil uygulamalara sahip olduklarını belirtmiştir. Bununla birlikte, söz konusu katılımcılar arasında uygulamayı her gün takip ettiğini ifade eden öğretmen adaylarının $(\mathrm{n}=37)$ bulunmasının yanı sıra uygulamayı nadiren takip ettiğini $(\mathrm{n}=14)$ ve hiç takip etmediğini $(\mathrm{n}=5)$ açıklayan katılımcıların da bulunduğu görülmüştür. Hava durumu mobil uygulamasına sahip olan ve uygulama verilerini her gün takip ettiğini ifade eden 11 katılımc1, günlük hayatta karşılaştıkları hava koşulları ile uygulamanın sunduğu veriler arasında herhangi bir karşılaştırma yapmadıklarını bildirmiştir. Buna ek olarak, öğretmen adaylarının günlük yaşamda sıklıkla karşılaşılan pastırma sıcakları gibi halk takvimi kavramlarının alt yapısı ve oluşumu hakkındaki düşüncelerinin tespit edilmesi ile gözlem kavramına yönelik görüşlerinin ortaya çıkarılması hedeflenmiştir. İnsanoğlunun yerleşik düzene geçmesi ile birlikte çiftçiliğe 
yönelmesi mevsimleri betimlemeyi oldukça önemli kılmış ve buna bağlı olarak neredeyse her bir coğrafik bölgenin kendine mahsus halk meteorolojisi ve halk takvimi oluşmuştur (Sever, 2005). $\mathrm{Bu}$ oluşum, belirli bir bölgede yaşayan insanların uzun süreli gözlem ve deneyimleri ile gerçekleşmiştir (Ayan, 2007; Sever, 2005; Sümbüllü, 2008). Bu noktada, çoğu katılımcının halk takviminin günlük ya da anlık olarak yapılan tahminlere dayandığını ya da bilimsel yöntemlerden hiçbirini barındırmadığı yönünde açıklamalarda bulunduğu görülmüştür. Buradan hareketle, öğretmen adaylarının günlük yaşamda karşılaştıkları olayları sorgulama ve değerlendirme noktasında eksiklik yaşadıkları sonucuna ulaşılmıştır. Bilimin doğası eğitiminde bireylerin günlük yaşamda karşılaştıkları olayları bilim, teknoloji ve toplum arasındaki etkileşimler çerçevesinde eleştirel olarak değerlendirmelerinin önemi vurgulanmaktadır (Albe, 2008).

Araştırmanın ikinci problemi, meteoroloji gözlem etkinliğinin tamamlanmasının ardından yürütülen görüşme verileri ile incelenmiştir. Bu noktada, çoğu öğretmen adayının hava durumuna ilişkin günlük verilerin daha tutarlı olduğunu ifade ettikleri görülmüştür. Bununla birlikte, ögretmen adayları uygulamadan elde ettikleri veriler ile gözlemledikleri hava durumu olaylarını kıyaslarken tespit ettikleri farklılık ve uyuşmazlıkları bilimsel bilginin yapılandırılmasında gözlemin rolüne ve özelliklerine odaklanarak açıklamıştır. Bazı katılımcılar ise küresel ısınma, çevre kirliliği gibi değişkenlerin 1şı̆̆ında hava durumu koşullarının farklılaşabildiğini ve beklenmedik değişimler gözlemlendiğini belirtmişlerdir. Bu kapsamda, öğretmen adaylarının meteoroloji gözlem etkinliği çerçevesinde elde etmiş oldukları gözlem sonuçlarını yorumlayarak çıkarımda bulunmaya başladıkları sonucuna ulaşılmıştır. Nitekim etkinlik süreci öncesinde uygulama verilerine kesinlikle inandığını ve bunların değişmez olduğunu açıklayan öğretmen adaylarının etkinliğin tamamlanmasının ardından gözlem verileri ile belirlenen sonuçların değişebildiğini ve bu bağlamda bilimsel yollarla elde edilen bilginin de değişebildiğini bildirdikleri görülmüştür. Bu tespit doğrultusunda, günlük yaşamda karşılaşılan durumları ele alan gözlem süreçleri dizayn edilerek öğretmen adaylarının eleştirel bir bakış açısıyla dünyayı değerlendirmelerinin sağlanması ve bu noktada daha fazla deneyim yaşamaları için imkân oluşturulmasının önemli olduğu düşünülmektedir. Örneğin, mevsim geçişleri esnasında ağaçlardaki değişim, hayvan göçleri gibi canlılar dünyasında görülen olayları içeren gözleme dayalı çeşitli etkinlikler düzenlenebilir. 


\section{KAYNAKLAR}

Abd-El-Khalick, F., Bell, R. L., \& Lederman, N. G. (1998). The nature of science and instructional practice: Making the unnatural natural. Science Education, 82(4), 417-436.

Abd-El-Khalick, F., \& Lederman, N. G. (2000). Improving science teachers' conceptions of nature of science: a critical review of the literature. International Journal of Science Education, 22(7), 665-701.

Akoğlu, A. (2005). Popüler bilim yayınc1lığı ve gökyüzü gözlem etkinlikleri. Journal of İstanbul Kültür University, 2, 1-4.

Albe, V. (2008). When scientific knowledge, daily life experience, epistemological and social considerations intersect: Students' argumentation in group discussions on a socio-scientific issue. Research in Science Education, 38(1), 67-90.

Ayan, D. (2007). Astronomik düzenlilikten sosyo-matematik uylaşıma takvim. Osmanlı Bilimi Araştırmaları, 9(1-2), 215-246.

Cohen, L., Manion, L., \& Morrison, K. (2007). Research methods in education. New York: Routledge.

Creswell, J. W. (2012). Educational research: Planning, conducting, and evaluating quantitative and qualitative research. Boston, MA: Pearson Education.

Creswell, J. W. (2013). Qualitative inquiry and research design: Choosing among five approaches. Thousand Oaks, CA: Sage.

Denzin, N. K., \& Lincoln, Y. S. (2000). Handbook of qualitative research. Thousand Oaks, CA: Sage

Kimball, M. E. (1967). Understanding the nature of science: A comparison of scientists and science teachers. Journal of Research in Science Teaching, 5(2), 110-120. CA: Sage.

Krippendorff, K. (2004). Content analysis: An introduction to its methodology. Thousand Oaks,

Lederman, N. G., Abd-El-Khalick, F., Bell, R. L., \& Schwartz, R. S. (2002). Views of nature of science questionnaire: Toward valid and meaningful assessment of learners' conceptions of nature of science. Journal of Research in Science Teaching, 39(6), 497-521.

Lederman, N. G. (2013). Nature of science: Past, present, and future. In Handbook of research on science education (pp. 845-894). Routledge.

Lightman, A. (1999). Yıldızların zamanı. (M. Alev, Çev.) İstanbul: Pro-Mat Basım Yayın.

Nokes, J. D. (2008). The observation/inference chart: Improving students' abilities to make inferences while reading nontraditional texts. Journal of Adolescent \& Adult Literacy, 51(7), 538-546.

Noor, K. B. M. (2008). Case study: A strategic research methodology. American Journal of Applied Sciences, 5(11), 1602-1604.

Schwartz, R. S., Lederman, N. G., \& Crawford, B. A. (2004). Developing views of nature of science in an authentic context: An explicit approach to bridging the gap between nature of science and scientific inquiry. Science Education, 88(4), 610-645.

Sever, R. (2005). Coğrafya öğretim programlarında doğal mevsim kavramı. Doğu Coğrafya Dergisi, 13, 117-134.

Sümbüllü, Y. Z. (2008). Halk meterolojisi ekseninde bir melheme örneği. Electronic Turkish Studies, 3(7), 782-811.

Şener, H. T., Demirhan, U., \& Kalyoncu, K. G. (2005). Çıplak gözle astronomi gözlemleri. Journal of İstanbul Kültür University, 3, 39-51.

Unat, Y. (2003). Astronomi tarihi. A. Cevizci (Ed.), Felsefe ansiklopedisi, içinde (s. 639 - 649). İstanbul: Etik Yayınları. 